\title{
Pancreatic stones: Treat or ignore?
}

\author{
DA Howell MD
}

\begin{abstract}
DA Howell. Pancreatic stones: Treat or ignore. Can J Gastroenterol 1999;5(6):461-465. Painful, chronic pancreatitis is of complex etiology, but increasing clinical experience suggests that removal of pancreatic duct stones in many cases significantly improves patients' symptoms. The development and refinement of therapeutic endoscopic retrograde choledochopancreatography have permitted improved access to the pancreatic duct, which makes the development of new techniques of stone fragmentation and fragment removal a much more successful nonsurgical intervention. A major step forward has been the understanding of the safety and efficacy of pancreatic sphincterotomy, which is necessary for the removal of these difficult stones. The recognition that extracorporeal shock wave lithotripsy can be delivered safely with good efficacy has revolutionized the nonsurgical management of pancreatic duct stones. Nevertheless, advanced and sophisticated therapeutic endoscopy is necessary to achieve clearance of the duct, which can generally be accomplished in the majority of selected patients. State-of-the-art treatments are described, and some new approaches using pancreatoscopy and electrohydrolic lithotripsy are discussed. Newly recognized long term complications are reviewed. Finally, it must be recognized that chronic pancreatitis is an ongoing disease that does not have a simple treatment or cure, and frequently represents a process of remissions and relapses requiring interventions and problem solving.
\end{abstract}

Key Words: Endoscopic retrograde choledochopancreatography; Endoscopy; Pancreatic stones

\section{Lithiase pancréatique : intervenir ou ne pas intervenir?}

L'étiologie de la pancréatite chronique, affection douloureuse, est difficile à cerner, mais de plus en plus d'expériences cliniques indiquent que l'extraction de calculs du canal pancréatique permet, dans de nombreux cas, un soulagement notable des symptômes de la maladie. La mise au point et le perfectionnement de la cholédocho-pancréatographie endoscopique thérapeutique par voie rétrograde offrent un meilleur accès au canal pancréatique, rendant ainsi les nouvelles techniques de fragmentation de calculs et d'extraction de fragments une intervention non chirurgicale beaucoup plus efficace qu'avant. Une des étapes importantes a été la compréhension de l'innocuité et de l'efficacité de la sphinctérotomie pancréatique, qui s'impose pour l'extraction de ces calculs difficiles. La reconnaissance de l'administration d'ondes de choc extracorporelles comme méthode sûre et efficace de lithothripsie a révolutionné le traitement non chirurgical des calculs logés dans le canal pancréatique. Le recours à des techniques avancées et délicates d'endoscopie thérapeutique s'avère toutefois nécessaire pour dégager le canal pancréatique, mais l'intervention ne pose généralement pas de problèmes dans la plupart des cas sélectionnés. Il sera donc question dans le présent article de traitements à la fine pointe de la technologie et de nouvelles avenues offertes par la pancréatoscopie et la lithotripsie électro-hydraulique. On passera également en revue des complications à long terme reconnues depuis peu. Enfin, il faut reconnaître que la pancréatite chronique est une maladie qui ne connaît pas de traitement simple ou de guérison; elle présente souvent des périodes de rémission et de rechute, qui nécessitent interventions et résolution de problèmes.
$\mathrm{T}$ he pain of chronic pancreatitis is of complex etiology. Many investigators have found pancreatic ductal hypertension, as well as increased tissue pressure, to be a nearly universal factor $(1,2)$. Ductal decompression by lateral pancreatojejunostomy is effective in relieving the pain of chronic pancreatitis in approximately $75 \%$ of patients with dilated ducts, often with intraductal stones, and serves as the rationale for endoscopic decompression by pancreatic sphincterotomy and stent placement. The role of obstructing stones in contributing to the pain of chronic pancreatitis has been controversial because not all patients benefit from ductal decompression. In fact, not all patients have pain relief following total pancreatectomy and/or celiac plexus neurolysis. Nevertheless, studies of endoscopic intervention aimed at improving ductal drainage with stent placement or pancreatic duct stone removal have reported marked clinical improvement in patients' pain scores varying from $50 \%$ to $93 \%$ of those of the total group treated (3-8). The potential for pancreatic duct stones to obstruct warrants consideration of removal, especially in patients who receive symptomatic benefit from temporary plastic stent placement.

At the Maine Medical Centre (Portland, Maine), we se-

Portland Gastroenterology Associates, Portland, Maine, USA

Correspondence and reprints: Dr DA Howell, Portland Gastroenterology Associates, 131 Chadwick Street, Portland, Maine 04102-3214, USA. Telephone 207-773-7954, fax 207-773-9073, e-mail puckem@poa.mmc.org 


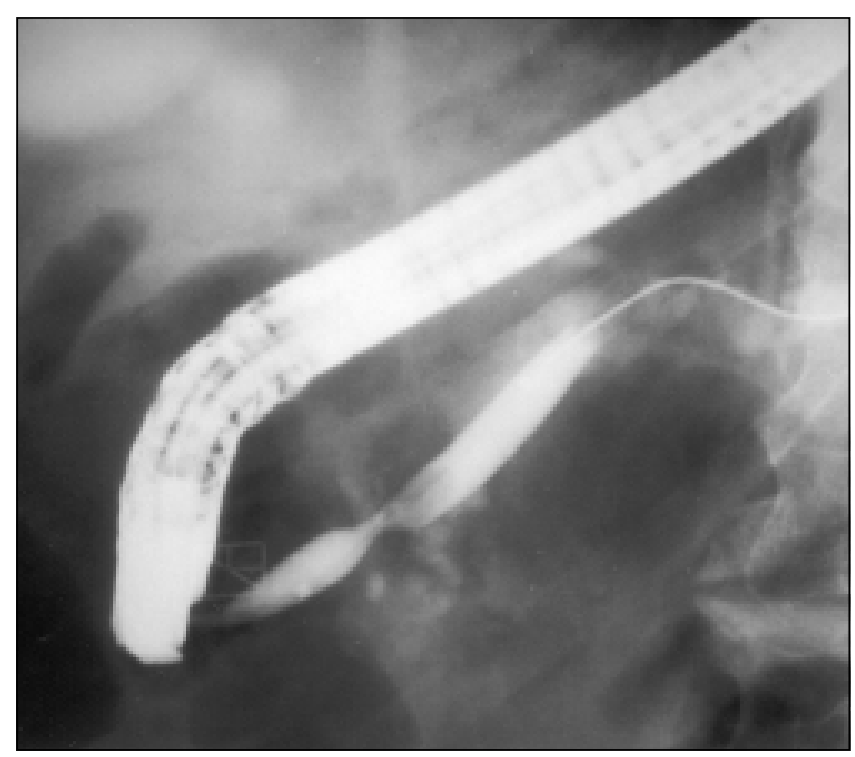

Figure 1) Balloon dilation. An $8 \mathrm{~mm}$ hydrostatic balloon is inflated to high pressure across a tight periampullary pancreatic ductal stricture. The calcified stone can be seen just above the balloon, and a tight waist remains. Several inflations may be necessary to maximize dilation, and strictures frequently do not completely dilate to the maximum balloon diameter, despite up to $2533 \mathrm{kPa}$ of pressure

lect patients who are most likely to benefit from ductal drainage using a variety of clinical and imaging criteria. First, we stipulate that patients not be actively abusing alcohol, are medically compliant and do not have a history or evidence of drug-seeking behaviour. We treat patients who are having intermittent acute attacks as well as patients with chronic pain. Patients with advanced disease characterized by exocrine insufficiency and insulin-dependent diabetes are not considered likely to benefit and generally have extensive ductal abnormalities with multiple stones. We do accept patients for stone removal who also have pancreatic ductal strictures and upstream associated pancreatic pseudocysts. These require more extensive techniques of endoscopic management, which are not covered in this article.

\section{ENDOSCOPIC MANAGEMENT}

Case selection, sphincterotomy and balloon dilation: The fundamental first step of endoscopic management is proper case selection. In addition to the factors outlined above, patients are much more likely to have complete stone clearance if they have a few stones rather than many. Stones located in the tail of the gland are technically very difficult to remove as are very large stones. Extensive ductal changes with 'chain of lakes' deformity or multiple dense strictures within the head of the gland indicate a low likelihood of clearance.

Virtually all patients require pancreatic sphincterotomy for stone removal, which can be done by either of two techniques (9). The first described and most widely employed procedure follows the placement of a pancreatic duct stent. A needle-knife sphincterotome incision is directed along the axis of the stent generally in the 1 to 2 o'clock position, proceeding until a rush of pancreatic juice is noted. The stent is then left in place to compensate for postsphincterotomy edema, which may lead to obstruction.

We prefer the technique of pull type sphincterotomy after insertion to the tail of the pancreas. This technique has the advantage of permitting further manipulations to be carried out during the same setting before placement of the stent or a temporary nasobiliary tube if the duct is cleared of the stones. Following pull type pancreatic sphincterotomy in 164 consecutive patients, we reported an overall complication rate of $1.8 \%(10)$. However, the complication rate was only $0.7 \%$ when postsphincterotomy drainage was performed with placement of a pancreatic stent or nasopancreatic drain. In addition, we believe that a wider sphincterotomy is possible using the pull type technique by extending the sphincterotomy by using a very small amount of introduced wire with the guidewire in place. It is often possible to extend the pancreatic sphincterotomy considerably after the initial rush of pancreatic juice is seen. The top of the cut is determined by assessing for a fall in current density with subsequent 'stalling' of the cutting wire, indicating that the duct is orienting deep in the duodenal wall. Using this technique, we do not employ the Erbe USA, Inc (Marietta, Georgia) electrosurgical generator because this unit increases the current density in response to increasing resistance to forward cutting. We have not yet experienced an episode of postpancreatic sphincterotomy perforation or serious bleeding. We perform sphincterotomy of the minor papilla in a similar fashion, although in general the direction of the cut is more leftward in the 11 o'clock position and the sphincterotomy cannot be extended as far.

The direct attack on the stone then is determined by the size, location, presence of strictures between the papilla and the stone, and the relative tightness of the stone within the duct. Frequently pancreatic stones are encysted with a very tight fibrotic reaction around them making basket removal problematic.

We frequently perform balloon dilation using a high pressure balloon in view of the very intense fibrosis associated with calculus chronic pancreatitis (Figure 1). Among 44 patients, we employed balloon dilation in 10 (23\%) using 8 or $10 \mathrm{~mm}$ Olert PVC-3 balloons (Microvasive, Watertown, Massachusetts), which deliver $2533 \mathrm{kPa}$ of pressure. We take care not to place the balloon alongside the stone because of the extremely hard nature of the calculi, which might induce tearing or rupture of the opposite wall of the duct. It is important to note that patients experience significant pain during balloon dilation and uniformly require additional conscious sedation. We have observed no other short term complications using the technique (11).

Stone removal: Following sphincterotomy and balloon dilation, an attempt to extract the stones can be made with an occlusion balloon placed over a guidewire. The presence of the guidewire insures the ability to re-enter the duct in case the stone is impacted by the effort to extract it using the balloon. The extreme hardness and sharp crystalline nature of pancreatic duct stones frequently induce rupture of the bal- 


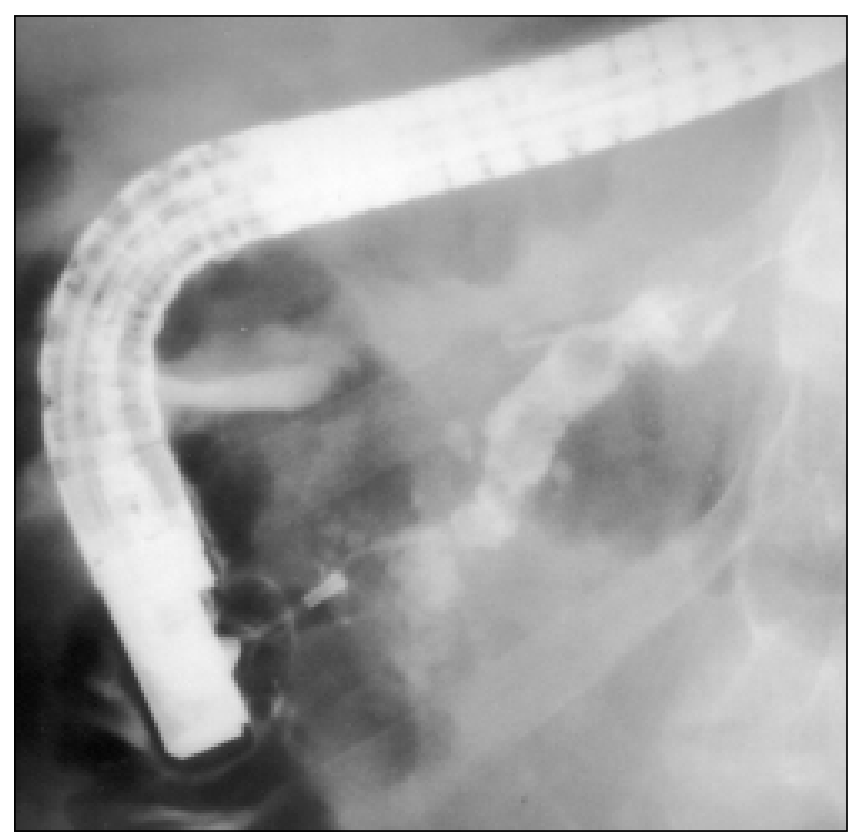

Figure 2) Contrast injection at endoscopic retrograde choledochopancreatography reveals multiple intraductal stones. Note the radiodense stone near the injection catheter of the same density as the contrast

loon. In addition, the vector of force during balloon extraction may drive the stone laterally into the wall, preventing extraction despite an adequately dilated tract. Importantly, pancreatic stones are frequently isodense compared with injected contrast, and extraction may be complicated by the inability to observe the stone under fluoroscopy (Figure 2). Minimizing contrast installation or flushing the duct with saline is occasionally necessary to permit direct observation during extraction techniques.

The employment of a Dormia basket (Figure 3) raises the possibility of basket entrapment, which we have experienced as a complication in our series. The employment of extracorporeal shock wave lithotripsy (ESWL) and the use of endoscopic retrograde cholangiopancreatography (ERCP) techniques to free the basket proved successful in our two experiences. As an adjunct to stone fragmentation, we employ a 7 French mechanical lithotripter (Olympus America Inc, Melville, New York) because the tip of the 10 French lithotripter is usually too large to negotiate the very small space between the fibrotic duct and stone. Mechanical lithotripsy is rarely successful because of difficulties of stone capture as well as the extreme hardness of the stones, which resist the forces of mechanical crushing.

Pancreatoscopy and electrohydraulic lithotripsy: The availability of through the scope 10 French cholangiopancreatoscopes (baby scopes) has made direct visual access to the pancreatic duct more possible, principally because of their small size. The mother-daughter scope system has been employed in the pancreatic duct, but the larger size of both scopes makes complete pancreatoscopy more difficult, and insertion is often limited by associated strictures. Using a new baby scope, we have developed preliminary experience with electrohydraulic lithotripsy in fragmenting pancreatic

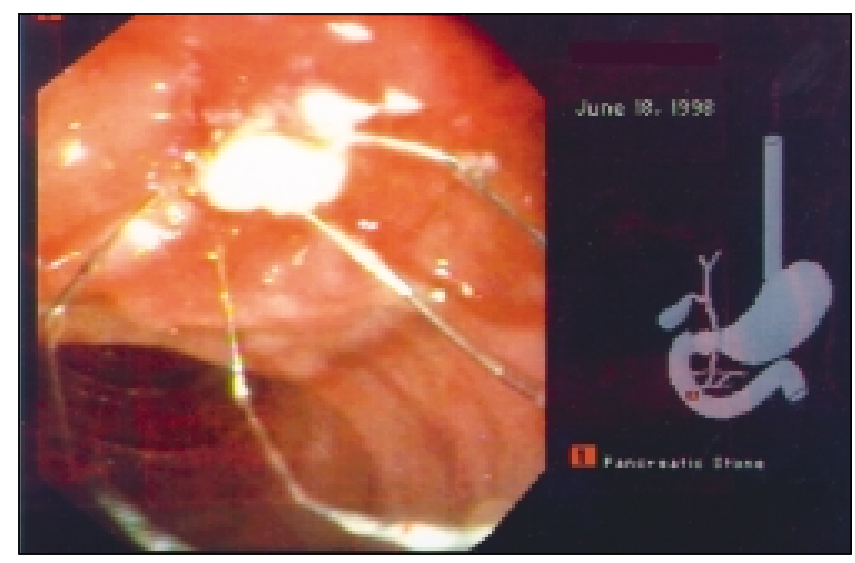

Figure 3) A 4 to $5 \mathrm{~mm}$ stone is extracted using a four-wire basket after general pancreatic sphincterotomy. Great care must be exercised in identifying stone size and ductal diameter to avoid stone basket entrapment

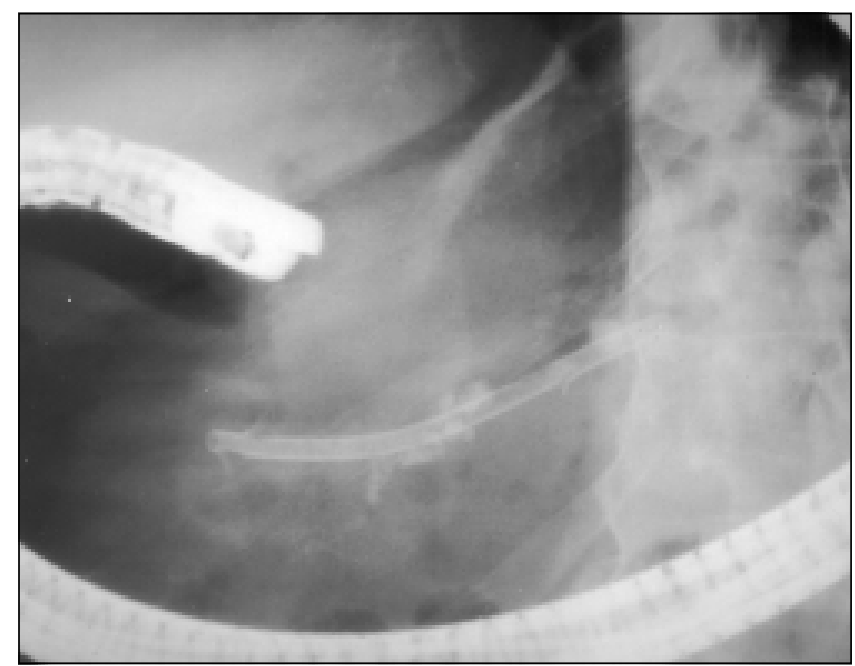

Figure 4) A temporary 7 French Geenen pancreatic stent has been placed around multiple calcified stones in preparation of extracorporeal shockwave lithotripsy after failing to extract them through the minor papilla in a patient with complete obstruction and fibrosis of the main pancreatic duct at the genu

duct stones. This technology uses readily available spark gap lithotripsy during saline infusion through the channel of the baby scope. We have been able to fragment partially stones that were insufficiently fragmented by extracorporeal lithotripsy, as well as treat a single patient with an extremely large stone as primary therapy. Experience is limited, but to date no serious side effects have been noted using power settings similar to those employed for common duct stone contact lithotripsy. Other authors have published preliminary experience using pulse dye lasers in an operative setting without serious complication $(12,13)$. Laser lithotripsy delivered by a $3.4 \mathrm{~mm}$ baby scope has been reported by the Munich group (14). Finally, after all techniques of endoscopic stone management have been completed, we believe it is important to confirm clearance of the duct by direct pancreatoscopy. This is especially apparent in view of the difficulties with isodense stones, which cannot be visualized in the presence of in- 
stilled radiocontrast. Small and even large fragments are frequently detected on pancreatoscopy despite having concluded that the duct has been completely cleared.

Drainage: It is important to provide pancreatic drainage following vigorous efforts at stone removal, especially in the setting of incomplete clearance or failure (Figure 4). Stent placement in the setting of an impacted pancreatic stone is quite difficult, but every effort should be made to pass the stent beyond the stone to ensure drainage. The employment of a Soehendra metal screw stent extractor (Wilson-Cook Medical, Winston Salem, North Carolina) can grind a groove even in a hard stone after a guidewire has been placed across the stone. In general, an 8.5 French extractor permits placement of a 7 French Geenen type pancreatic stent, and a 10 French stent extractor permits placement of an 8.5 French stent. Measuring the length of the stent is important because the course of the pancreatic duct is generally toward the fluoroscope in the head and neck region in the usual ERCP patient positioning. If the patient is to undergo prompt ESWL, we often insert a 5 or 6 French nasopancreatic drain, which is particularly valuable in targeting the offending stone when multiple calcifications may exist within the side branches or parenchyma of the gland. In addition, this ensures drainage in the postoperative period if repeat ERCP is to be done promptly.

ESWL: Because of the technical difficulties of stone extraction using endoscopic methods, electrohydraulic shock wave lithotripsy has proved to be a major form of adjunctive therapy in nonoperative duct clearance. More than 300 patients treated with ESWL have been reported to the literature. The largest reported experiences have been with 123 patients reported in 1992 (15) and with 70 new patients in a more recent report (4). Many other centres have reported similar successful results with ESWL using a variety of machines $(6-8,12,15-18)$. The general consensus is that ESWL is extremely safe, with only a few reported complications related to the treatment itself, including a single intramural hematoma and a few instances of mild post-treatment pancreatitis. It is possible that the piezoelectric machine (16), which is less powerful than the electromagnetic or electrohydraulic machines, is less successful, although randomized data are not available. Bidirectional fluoroscopic $\mathrm{x}$-ray focusing is desirable because ultrasound may have difficulty targeting the stone in the presence of overlying bowel gas and with multiple adjacent calcifications. Some centres permit spontaneous passage of fragmented stones, but most proceed with post-treatment ERCP for clearance of fragments and confirmation of duct clearance, which is our preferred approach. One study from Japan reported a complete clearance of stones in 24 of 32 patients (75\%) after multiple ESWL treatments (mean $=4.6$ ) without any therapeutic ERCP (7). This technique has not been confirmed in other centres, and a cost-benefit analysis was not provided. Because the mean number of treatments in other larger series that employed adjunctive therapeutic ERCP was significantly lower (ie, 1.8 sessions [14]), this approach seems likely to be significantly more costly.

\section{COMPLICATIONS}

Surprisingly few complications of endoscopically managed patients have been reported. Notably, most patients are treated in advanced centres of endoscopic excellence where these often complex procedures are frequently done. Similar low complication rates may not be achievable in hospitals with a low volume of complex cases. Nevertheless, patients with chronic pancreatitis likely have a lower risk of acute pancreatitis with only a single such instance among 53 patients in Amsterdam (6) and none among 44 patients in our series. Entrapped baskets, which, in our experience, may respond to an additional treatment with ESWL, have been reported in other centres (9).

Pancreatic sepsis has been reported as a consequence of both pancreatic stent occlusion and incomplete pancreatic drainage (15). Pancreatic infections complicated these series $4 \%$ to $20 \%$ of the time, which by one author was described as 'pancreatic cholangitis' due to impaction of fragments following ESWL. In general, these episodes of infection were considered minor and generally responded to antibiotics, clearance of fragments and/or temporary stent placement. Overall complication rates range from $8 \%$ to $38 \%$, with the death rate under $1 \%$ in all series.

The need for surgery varies widely depending on case selection and is employed in patients who have persistent symptoms despite clearance of the duct, failed cases, and where significant complications such as perforation or severe postsphincterotomy bleeding occur. Surgical rates range from $5 \%$ to $25 \%$ and emphasize the importance of a team approach to endoscopic management of pancreatic stones.

\section{RESULTS}

Symptomatic improvement has been uniformly reported in all centres employing techniques of nonsurgical management of pancreatolithiasis. Response of rates approaching $95 \%$ of at least partial improvement have been noted. A range of response from $50 \%$ to $93 \%$ with follow-ups approaching four years underscores the value of these treatments in this difficult group of patients. Treatment results and techniques of management are summarized in $\mathrm{Ta}$ ble 1 .

\section{RECURRENCE AND LATE COMPLICATIONS}

A few authors have reported recurrence and late complications. Costamagna et al (3) noted 22 pain relapses occurring in nine of his 35 ESWL-treated patients. Occlusion of indwelling pancreatic stents and recurrence of pancreatic ductal strictures explained most of the occurrences. However, he did note that four patients $(11 \%)$ of the total developed recurrent obstructing stones that were thought to be due to migration of side branch stones.

We have experienced six recurrent pancreatic duct stone obstructions in five of 44 patients (11\%) occurring between three months and 23 months after cessation of endoscopic intervention, including withdrawal of pancreatic duct stents (19). What was more significant was that in four of these patients, infection complicated the reobstruction including ab- 
TABLE 1

Summary of treatment techniques and results

\begin{tabular}{|c|c|c|c|c|c|c|}
\hline Author, year (reference) & $\begin{array}{c}\text { Number of } \\
\text { patients }\end{array}$ & $\begin{array}{l}\text { Treatment } \\
\text { modality }\end{array}$ & $\begin{array}{c}\text { Complete ductal } \\
\text { clearance }\end{array}$ & Improved pain & $\begin{array}{l}\text { Follow-up, months } \\
\text { (mean) }\end{array}$ & Complications \\
\hline Sherman et al, 1991 (5) & 32 & Endoscopic & $23(72 \%)$ & $22(68 \%)$ & 6 to 91 & $4(12 \%)$ \\
\hline Sauerbruch et al, 1992 (8) & 24 & Multimodal & $10(42 \%)$ & $12(50 \%)$ & 3 to $55(24)$ & not stated \\
\hline Delhaye et al, 1992 (15) & 123 & Multimodal & $72(59 \%)$ & 75/88 (85\%) & not stated & $53(43 \%)$ \\
\hline Smits et al, 1996 (6) & 53 & Multimodal & $39(73 \%)$ & $38(71 \%)$ & 4 to $131(33)$ & $5(9 \%)$ \\
\hline Ohara et al, 1996 (7) & 32 & ESWL & $24(75 \%)$ & $25(79 \%)$ & 16 to $63(44)$ & None \\
\hline Present study & 44 & Multimodal & $32(72 \%)$ & 41 (93\%) & 2 to $68(22)$ & $6(14 \%)$ \\
\hline Total & 343 & & $226(66 \%)$ & $238(69 \%)$ & $\sim 30$ & $76(22 \%)$ \\
\hline
\end{tabular}

ESWL Extracorporeal shockwave lithotripsy

scess formation in three and a pancreatic ductal infection with purulent discharge in one. After initial percutaneous drainage in an outside hospital, one patient returned with recurrence of the abscess requiring repeat endoscopic intervention. This incidence of $9 \%$ late infection is cause for concern, but the infections were managed successfully with stent placement in four and with urgent surgical drainage in two. Elective lateral pancreatojejunostomy was performed after clearance of the sepsis by stent placement in an additional patient. The rarity of spontaneous pancreatic infection in the setting of pancreatolithiasis suggests that prior endoscopic manipulation predisposes patients to infection when there is reobstruction likely secondary to colonization of the duct and stone material due to previous ablation of the sphincter. This incidence of late infection has not been reported by other authors but, if confirmed, may require a reevaluation of the alternatives to pancreatic sphincterotomy during pancreatic duct stone removal.

\section{REFERENCES}

1. Bradley EL. Pancreatic duct pressure in chronic pancreatitis. Am J Surg 1982;144:313-6.

2. Jalieh RP, Asiam M, Williamson RCN. Pancreatic tissue and ductal pressures in chronic pancreatitis. Br J Surg 1991;78:1235-7.

3. Costamagna G, Gabbrielli A, Mutignani M, et al. Extracorporeal shock wave lithotripsy of pancreatic stones in chronic pancreatitis: immediate and medium-term results. Gastrointest Endosc 1997;46:231-6.

4. Dumonceau JM, Deviere J, Le Moine O, et al. Endoscopic pancreatic drainage in chronic pancreatitis associated with ductal stones: long-term results. Gastrointest Endosc 1996;43:547-55.

5. Sherman S, Lehman GA, Hawes RH, et al. Pancreatic ductal stones: frequency of successful endoscopic removal and improvement in symptoms. Gastrointest Endosc 1991;37:511-7.

6. Smits ME, Rauws EA, Tytgat GN, Huibregtse K. Endoscopic treatment of pancreatic stones in patients with chronic pancreatitis. Gastrointest Endosc 1996;43:556-60.

7. Ohara H, Hoshino M, Hayakawa T, et al. Single application extracorporeal shock wave lithotripsy is the first choice for patients with pancreatic duct stones. Am J Gastroenterol 1996;91:1388-94.

8. Sauerbruch T, Holl J, Sackmann M, Paumgartner G. Extracorporeal lithotripsy of pancreatic stones in patients with chronic pancreatitis and pain: a prospective follow up study. Gut 1992;33:969-72.

9. Kozarek RA, Ball TJ, Patterson DJ, Brandabur JJ, Traverso LW, Raltz S. Endoscopic pancreatic duct sphincterotomy; indications, technique, and analysis of results. Gastrointest Endosc 1994;40:592-8.

10. Elton E, Howell DA, Parsons WG, Qaseem T, Hanson BL.

\section{CONCLUSIONS}

The clinical success in improving pain scores, preventing recurrent painful episodes, and avoiding hospitalizations following nonsurgical techniques of pancreatic duct stone removal support intervention in many patients with intraductal calculi. Care should be used in selecting cases to optimize the likelihood of nonsurgical duct clearance in patients who are not actively abusing alcohol or drug seeking. Techniques to clear the duct are improving but frequently require staged therapy with multiple sessions of intervention. Candidates for this form of treatment should be understanding, motivated and compliant. The development of intraductal therapy with miniscopes holds promise of increased success and lower costs. Recent experience with late pancreatic infections raises concern that transpapillary drainage may be insufficient at times and predispose a subset of patients who continue to suffer from the long term consequences of this debilitating disease to late infection.

Endoscopic pancreatic sphincterotomy: indications, outcome, and a safe stentless technique. Gastrointest Endosc 1998;47:240-9.

11. Ku PM, Hanson BL, Elton E, Howell DA. Balloon dilation of pancreatic strictures for stone removal is safe and improves successful endoscopic clearance. Gastroinest Endosc 1998;48:456. (Abst)

12. Craigie JE, Adams DB, Byme TK, et al. Endoscopic electrohydraulic lithotripsy in the management of pancreatobiliary lithiasis. Surg Endosc 1998;12:405-8.

13. Tanaka M, Yokohata K, Kimura H, Naritomi G, Ichimiya H, Minasi JS. Intraoperative endoscopic electrohydraulic lithotripsy of pancreatic stone. Int J Pancreatol 1992;12;227-31.

14. Neuhaus H, Hoffmann W, Classen. Laser lithotripsy of pancreatic and biliary stones via $3.4 \mathrm{~mm}$ and $3.7 \mathrm{~mm}$ miniscopes: First clinical results. Endoscopy 1992;24:208-14.

15. Delhaye M, Vandermeeren A, Baize M, Cremer M. Extracorporeal shock-wave lithotripsy of pancreatic calculi. Gastroenterology 1992;102:610-20.

16. Schneider HT, May A, Benninger J, et al. Piezoelectric shock wave lithotripsy of pancreatic duct stones. Am J Gastroenterol 1994;89:2042-8.

17. Matthews K, Correa RJ, Gibbons RP, Weissman RM, Kozarek RA. Extracorporeal shock wave lithotripsy for obstructing pancreatic duct calculi. J Urol 1997;158:522-5.

18. Martin RF, Hanson BL, Bosco JJ, et al. Combined modality treatment of symptomatic pancreatic ductal lithiasis. Arch Surg 1995; 130:379-80.

19. Hanson BK, Howell DA, Elton E, et al. Obstructing pancreatic duct stones: success and delayed complications of endoscopic management. Gastrointest Endosc 1998;47:451. (Abst) 


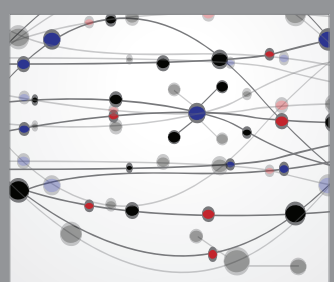

The Scientific World Journal
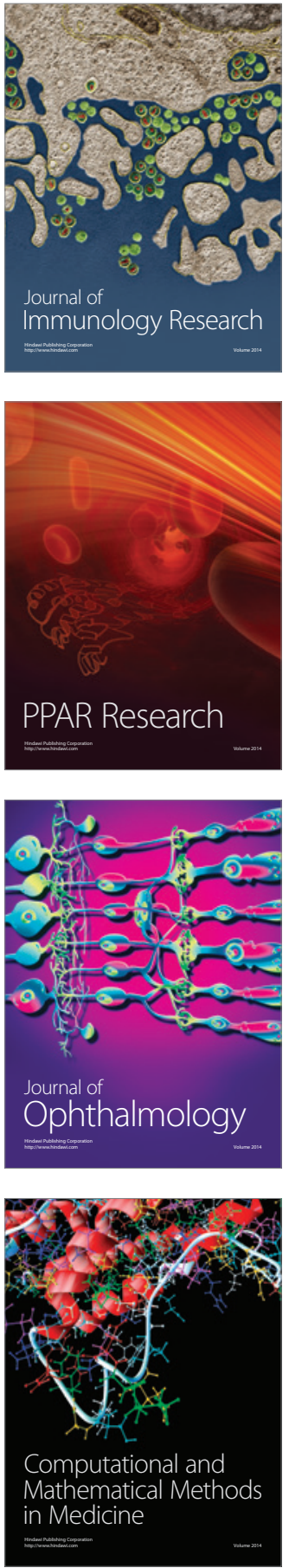

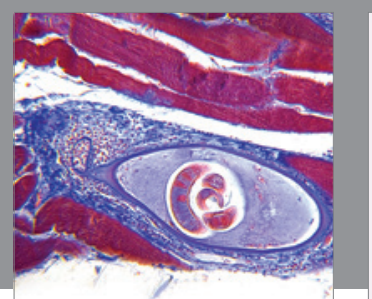

Gastroenterology Research and Practice

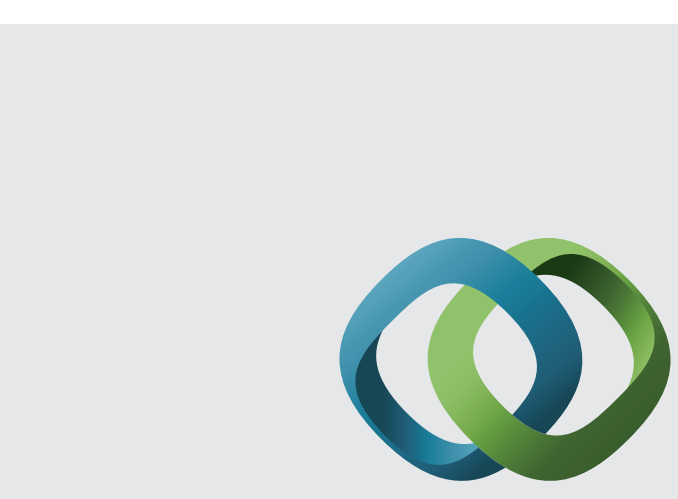

\section{Hindawi}

Submit your manuscripts at

http://www.hindawi.com
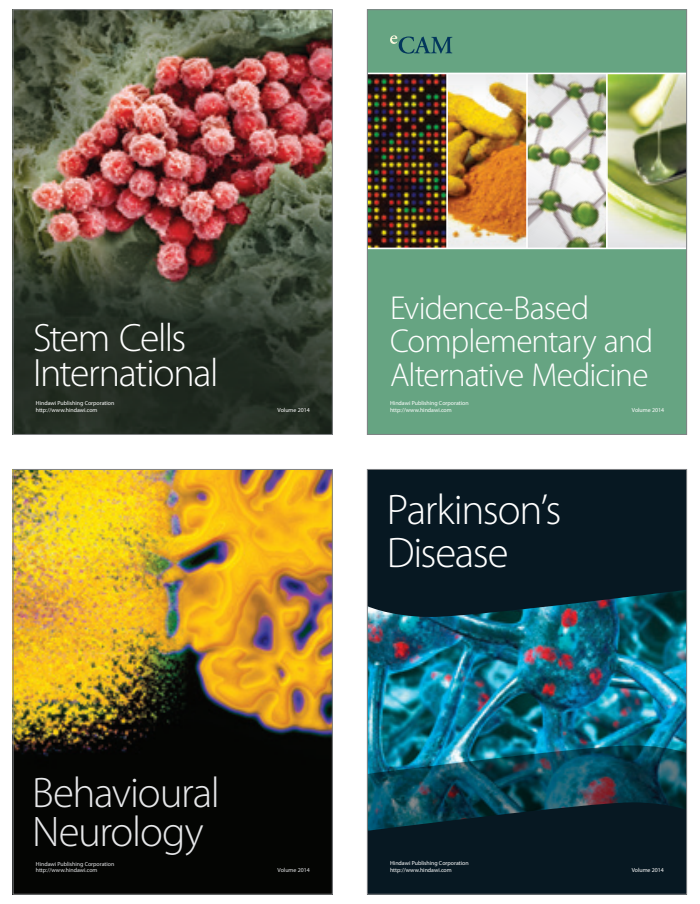
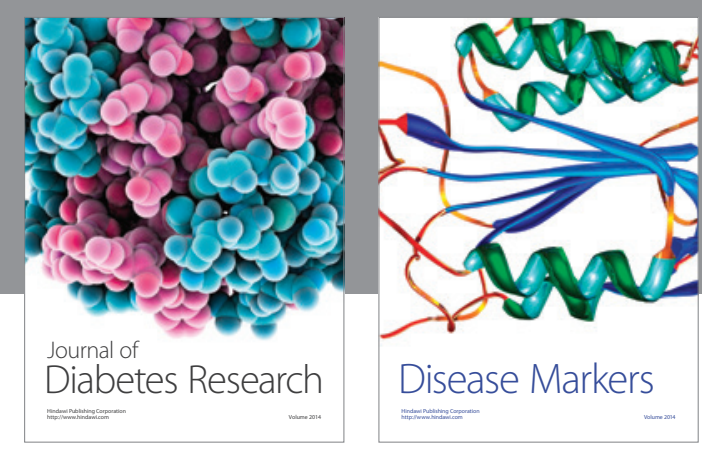

Disease Markers
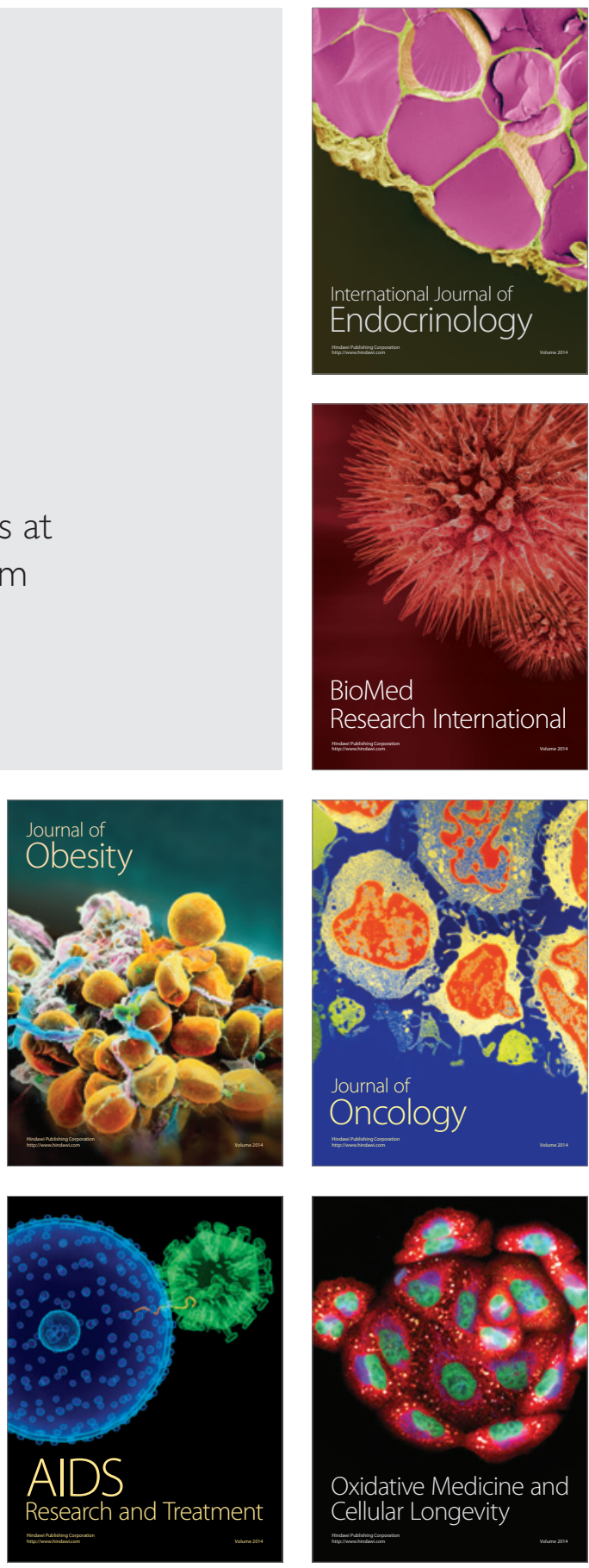